\title{
Starch and Pectin Affect Hardness of Cooked Bananas
}

\author{
Samuel Gafuma ${ }^{1}$, Diriisa Mugampoza ${ }^{1} \&$ G. W. Byarugaba-Bazirake ${ }^{1}$ \\ ${ }^{1}$ Department of Food Technology, Faculty of Science, Kyambogo University, Kampala, Uganda \\ Correspondence: Diriisa Mugampoza, Department of Food Technology, Kyambogo University, Kampala. P. O. \\ Box 1 Kyambogo, Kampala, Uganda. Tel: 256-781-713-555/256-705-345-507. E-mail: mugampoza@ gmail.com
}

Received: August 18, $2018 \quad$ Accepted: September 1, $2018 \quad$ Online Published: October 16, 2018
doi:10.5539/jfr.v7n6p107
URL: https://doi.org/10.5539/jfr.v7n6p107

\begin{abstract}
Texture is an important quality attribute of fresh and processed foods. In plant foods, texture is closely related with the structural integrity of the primary cell walls and middle lamella that is mainly composed of pectic substances. Bananas mainly contain water, starch, pectin and fibre which influence texture. Cooking bananas soften on cooking but harden on cooling. Despite many studies on retrogradation of starch and its effects on texture, little is known about the effect of added starch and/or breakdown of pectin on hardness of bananas upon cooking and cooling. In this study, the effects of added pectin and starch and structural elimination of pectin on hardness of bananas during cooking and cooling were investigated.

Hydrolysis of pectin resulted in significantly harder bananas during cooking and upon cooling $(\mathrm{P}<0.05)$. Hardness of starch-treated bananas increased significantly with increasing starch concentration upon cooking and cooling relative to the control $(\mathrm{P}<0.05)$. However, treatment of bananas with added pectin alone resulted in an insignificant increase in hardness relative to the control. Upon cooling, hardness of pectin-treated bananas decreased significantly with increasing pectin concentration $(\mathrm{P}<0.05)$. Hardness of cooked bananas treated with a combination of starch and pectin increased but was not significantly different from the control. Upon cooling, hardness of the starch-pectin treated bananas decreased with increasing concentration similar to the effect of pectin when added alone.

Current results showed that starch addition increases hardness of bananas upon cooking and cooling. However, pectin addition decreases hardness of cooked bananas upon cooling while structural elimination of pectin increases hardness upon cooking and cooling. These results imply that pectin contributes to a softer texture of bananas during cooking and cooling whereas starch increases hardness in cooked bananas. Pectin can therefore be added up to $5 \%$ to decrease hardness of cooked bananas.
\end{abstract}

Keywords: added starch, added pectin, cooked bananas, effect, textural hardness, structural pectin elimination

\section{Introduction}

\subsection{Background}

Texture is a group of physical characteristics that arise from the structural elements of a food perceived by the sense of touch, which are related to deformation, disintegration and flow of food under force, and measured objectively by functions of mass, time and distance (Bourne, 2002). It is a major sensory and quality attribute that plays an important role when assessing the quality of food. The texture of foods is related to the structure formed by micro and macro molecular elements forming the cell wall and other regions. The major challenge to cooking and consumption of bananas is their susceptibility to hardening of the texture after cooling. Changes in the texture of bananas affect other attributes such as flavor and /or taste which are lost upon cooling.

Changes in the texture of bananas during cooking are caused by structural changes in starch, pectin, cellulose and hemicellulose. The basic structure of the primary cell wall consists of a cellulose-hemicellulose network with pectin interwoven within this network forming the basis for structural integrity of the cell. In raw plant foods, pectin which is mainly found in the middle lamella, cements cell walls together and gives firmness and elasticity to plant tissues.

Cooking affects the structural integrity and biochemical composition of the cells and cell walls leading to loss of turgor pressure and the 'fresh' texture of bananas. Starch which is the most important carbohydrate and a major component in bananas undergoes gelatinization during cooking and retrogradation upon cooling which affect the 
final hardness of cooked bananas. These changes are major determinants of starch's functional properties, quality attributes, nutritional and shelf-life of finished products (Wang \& Copeland, 2013). According to Espinosa Solis, Jay - lin, \& Bello - Perez (2009), gelatinized banana starch during storage has the largest thermal stability because its crystals dissociate at higher temperatures and with a larger enthalpy change; which implies that a higher degree of crystallinity is produced in banana starch than in the other starches. This means that retrograded banana starch is very stable hence when bananas are cooked and allowed to cool and harden, reversing the hardened texture is almost impossible. This is exactly what consumers of cooked bananas in Uganda experience upon reheating of cooled bananas. When cooked, bananas soften but upon cooling, they irreversibly become hard. The tendency of cooked banana texture to harden during cooling has been objectively proven by Gafuma, Byarugaba-Bazirake, \& Mugampoza (2018).

The pectin content of raw green mature bananas consists majorly of protopectin which is characterized by a high degree of esterification (D.E) ranging between 88 to $96 \%$ (personal communication of unpublished results). Pectin consists of a linear chain of $\alpha$ - $(1 \rightarrow 4)$-linked D-galacturonic acid units in which varying proportions of acid groups are esterified with methyl groups which are responsible for gel formation during heating in presence of sugar and divalent cations such as $\mathrm{Ca}^{2+}$. This property affects water binding and holding properties of pectin which in turn may have significant influence on hardness of cooked bananas. Structural elimination of pectin can be performed by hydrolysis using pectinases majorly Polygalacturonase (PG) and Pectinmetylesterase (PME) which are the key enzymes responsible for pectin breakdown (Tapre \& Jain, 2014) in plant tissues causing softening as fruits and vegetables mature and ripen. During ripening, PME removes methyl ester groups from the cell wall pectic substances, making them accessible to depolymerisation by PG which in turn reduces intercellular adhesiveness and tissue rigidity (Payasi, Mishra, Chaves, \& Singh, 2009). Much as PME causes softening during ripening of fruits, it also increases firmness of fruits and vegetables via demethylation of endogenous pectin and subsequent chelation of divalent cations by ionized carboxyl groups on adjacent pectic acids (Jongen, 2002). Most commercial preparations of pectinases are produced from fungal sources (Sharma, Rathore, \& Sharma, 2012) with the commonest source being Aspergillus niger (Gummadi \& Panda, 2003). Depending on the need, these pectic enzymes can be used as processing aids particularly in the production of fruit juices. Due to the adhesive nature of pectin within plant tissues, it is not clear what would happen to the texture of bananas upon cooking and cooling if pectin is eliminated from their structural matrix. Currently, besides foods such as cheese where the effect of added pectin on texture has been studied, there is no information regarding the effect of structural elimination of pectin using pectinases, let alone added pectin on hardness of cooked bananas. Similarly, there is scant information on the effect of added starch on the hardness of cooked bananas. This study aimed to investigate the effects of added starch and pectin and structural elimination of pectin on hardness of bananas upon cooking and cooling.

Understanding these effects would promote innovation of cooked banana products that have more industrial and economic value. One of the challenges to cooked banana processing has been how to use recent advances in processing technologies to adjust raw banana composition, innovation of creative ingredient mix and processes to improve the texture of cooked bananas. As a result, future banana processors would produce banana products of a more desirable softer texture and flavor.

\section{Materials and Methods}

\subsection{Materials}

Three East African Highland Banana (AAA-EA) cultivars endemic to Uganda were selected for this study. These include Kayinja (KAY), a local juice banana cultivar from Central and Western Uganda under the Bluggoes ABB clone set and two cooking banana cultivars namely Kazirakwe (KAZ), a local cooking banana cultivar common in Western Uganda under the Nakabululu clone set; and Nakitembe (NAKT), a local cooking banana cultivar from Central Uganda under the Nakitembe clone set (Karamura, 1998). KAZ and NAKT were purchased from Kawanda Agricultural Research Institute (KARI) while KAY was bought from a farm near Kyengera trading centre in Wakiso district, Uganda. All samples were harvested and immediately transported to Makerere University Food Science and Nutrition laboratory for texture analysis. Pectin (CAS 9000-69-5; 75\% D.E) and the enzyme pectinase (CAS: 9032-75-1; activity $1 \mathrm{U} / \mathrm{mg}$ ) were purchased from Sigma Aldrich (USA) through Kobian Scientific, a local agent. Banana starch was locally extracted from NAKT banana cultivar using the alkaline starch extraction method (Zhang, Whistler, BeMiller, \& Hamaker, 2005). Other materials were obtained from local supermarkets.

\subsection{General Preparation of Banana Samples for Treatments}

Banana fingers (21) were picked from green mature banana bunches ( 7 from the top, middle and bottom), then 
washed, peeled and dipped in portable water to prevent browning. The peeled bananas were sliced to approx. $1-$ $2 \mathrm{~mm}$ discs and subdivided into three equal portions. Each portion was placed in a glass beaker and covered with aluminium foil before being weighed.

\subsection{Preparation of Pectinase-treated Bananas}

Approx. $240 \mathrm{~g}$ of sliced banana sample was weighed into a beaker. Then, $1.5 \mathrm{~g}$ of pectinase (polygalacturonase) was weighed and mixed well with $410 \mathrm{ml}$ of distilled water. The banana sample was mixed into the enzyme solution and the $\mathrm{pH}$ of the banana-enzyme mixture measured to be 5.3. The enzyme-banana mixture as well as the control were incubated at $50^{\circ} \mathrm{C}$ for $2 \mathrm{~h}$ in a water bath with constant agitation. After incubation, the solutions in the enzyme-treated bananas and the control were drained and the banana slices lightly squeezed in a nylon cloth to remove excess water. Each of the control and the enzyme-treated bananas were placed in a small plastic bag of 30 microns which was perforated to allow normal exchange of air and moisture. The bag containing the banana sample was steamed in a 3 Tier Food Steamer (HS6000, Black \& Decker, China) for 30 min, and thereafter removed and mashed. The mashed bananas were returned to the steamer and steamed for a further 20 min (50 min of cooking overall) before the first sample was taken for texture analysis. The bananas were steamed further for 70, 90, 110 and $130 \mathrm{~min}$ and appropriately sampled for texture analysis. The remaining banana masses for each replicate of the respective treatments were rolled together, cooled for $4 \mathrm{~h}$ at room temperature $\left(25^{\circ} \mathrm{C}\right)$ and used to measure texture of the cool samples. Mean values were tabulated and used to generate a profile of curves used for analysis of changes in textural hardness of the enzyme treated bananas.

\subsection{Preparation of Starch and Pectin-treated Bananas}

For each of starch and pectin treatments, $0(0 \%), 1(1.7 \%), 3(5 \%), 5(8.3 \%)$, and $7 \mathrm{~g}(11.7 \%)$ of banana starch extracted from Nakitembe according to the protocol of Gafuma et al. (2018) and pectin (Sigma) were weighed separately. Approx. $60 \mathrm{~g}$ of sliced bananas (section 2.2) were weighed into a plastic bag of 30 microns. The weighed starch or pectin was dispersed onto the banana slices carefully little by little from a plastic sieve by tapping the sieve while agitating the bananas to ensure uniform distribution. The plastic bag for each treatment was perforated at the upper side to prevent buildup of internal pressure and to allow normal exchange of air and moisture during steaming. A control for each treatment was prepared and comprised of bananas without added starch or pectin. The bananas were cooked by steaming in a Food Steamer for $30 \mathrm{~min}$ as in section 2.3 before being mashed. The mashed bananas were placed back into the steamer and steamed for a further $20 \mathrm{~min}(50 \mathrm{~min}$ of cooking overall) before sampling for texture analysis (Gafuma et al. 2018). The remaining banana masses were treated as in section 2.3 before being used to measure texture of the cool samples. Treatments were conducted in three independent replicates.

\subsection{Preparation of Starch-pectin Composite Treated Bananas}

Sliced bananas $(60 \mathrm{~g})$ from section 2.2 were weighed into a plastic bag as in section 2.3. Then, a starch-pectin composite was prepared by weighing $0,1,3,5$, and $7 \mathrm{~g}$ of banana starch and $0,1,3,5$, and $7 \mathrm{~g}$ of pectin (Sigma) separately. The starch and pectin powders were mixed thoroughly in a 1:1 ratio to achieve uniform composites of the different levels $(0-11.7 \%)$ of treatment. The starch-pectin composites were applied onto the banana slices $(3.33,10,16.7$ and $23.3 \%$ composite) and the treated samples processed as in section 2.3.

\subsection{Determination of Textural Hardness and Cohesiveness}

Textural hardness analysis was performed using a Texture Analyzer (TA.XT plus stable micro-systems, Surrey, $U K$ ) according to the method of Gafuma et al. (2018). Cohesiveness was defined as the ratio of the area under the second penetration curve to the area under the first penetration and values were generated by the Texture Analyzer according to the manufacturer's instructions (Texture technologies Corp. and Stable Micro Systems, 2018).

\subsection{Statistical Analysis}

Data were analyzed using IBM (SPSS) package, version 23. All means were split and separated by group and analyzed using one-way Analysis of Variance (ANOVA) using Fisher's Least Significant Difference (LSD) and Turkey's test procedures. Means were tested for homogeneity of variance and significant differences were determined at $\mathrm{P}<0.05$.

\section{Results}

\subsection{Introduction}

Bananas were sliced to increase the surface area for enhanced enzyme activity and ensure uniform distribution of, and contact with, starch and pectin. Pectinase-treated bananas were incubated with pectinase (polygalacturonase) 
to allow breakdown and structural elimination of pectin from the bananas. Treated bananas were steamed in a plastic bag to allow easy handling of the small sized samples during cooking and sampling. The effect of added pectin and starch on texture was examined using cooking bananas while the effect of structural elimination of pectin was investigated using cooking and juice bananas. The slicing of bananas in effect affected the texture by decreasing hardness of the samples meaning the texture of these samples (control) could not be directly compared with texture of the same intact (unsliced) banana samples.

\subsection{Effect of Pectin-treatment on Hardness}

Hardness of pectin-treated bananas was slightly higher than the control and increased with increasing pectin concentration up to $5 \%$ then it decreased as pectin concentration increased (Figure 1A, curve (b). Hardness increased from $0.93 \mathrm{~N}$ (control) through 1.04 to $1.24 \mathrm{~N}$ at 1.7 and $5 \%$ added pectin, respectively. Further increase in pectin concentration resulted in a decrease in hardness to 1.14 and $1.06 \mathrm{~N}$ at $8.3 \%$ and $11.7 \%$ added pectin, respectively with a weak positive correlation of $18.3 \%$. Overall, there was no significant difference between hardness of pectin-treated bananas and the control $(\mathrm{P}>0.05)$. Upon cooling, hardness generally increased probably due to retrogradation of starch (Wang, Li, Copeland, Niu, \& Wang, 2015). However, hardness of the control was profoundly higher than that of pectin-treated bananas and decreased with increasing pectin concentration from $4.50(1.7 \%)$ to $1.87 \mathrm{~N}(8.3 \%)$ followed by a slight increase to $1.92 \mathrm{~N}$ at $11.7 \%$ added pectin (Figure 1A, curve (a) with a strong negative correlation of $80.4 \%$. Hardness of the control and at $1.7 \%$ added pectin was not significantly different $(\mathrm{P}>0.05)$ but were significantly higher than hardness at other levels of added pectin (Figure 1A, curve (a).

Cohesiveness of pectin-treated bananas was higher than the control $(0.84 \mathrm{~N})$ and increased with increasing pectin concentration from 1.01 to $1.34 \mathrm{~N}$ upon cooking (Figure 1B, curve (b). Upon cooling, there was a general increase in cohesiveness of the control and pectin-treated bananas probably due to retrogradation of starch. However, cohesiveness of pectin-treated bananas $(2.99$ to $1.67 \mathrm{~N})$ was lower than that of the control $(3.02 \mathrm{~N})$ and decreased with increasing added pectin concentration from 2.99 (1.7\% pectin) to $1.67 \mathrm{~N}$ (8.3\% pectin) and then slightly increased again to $1.81 \mathrm{~N}$ at $11.7 \%$ added pectin (Figure 1B, curve (a).
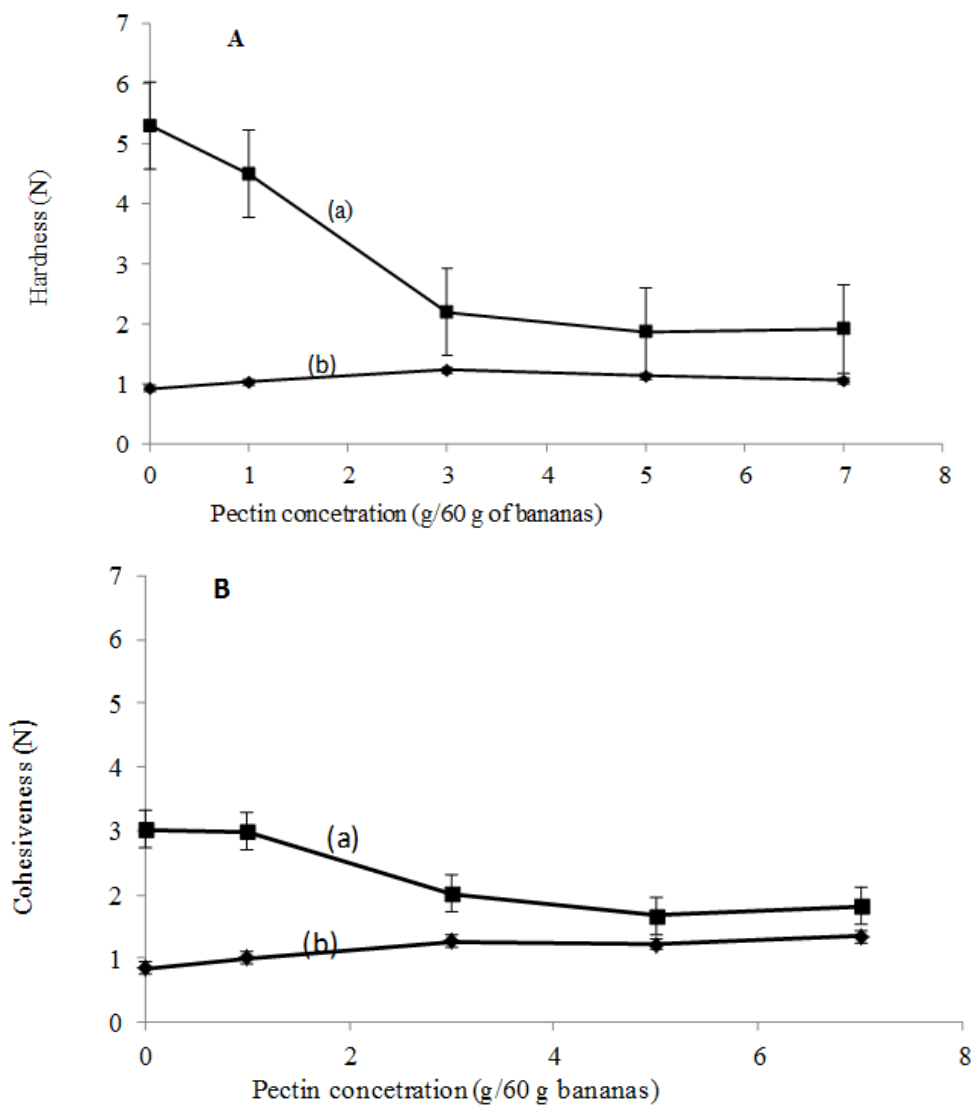

Figure 1. Effect of added pectin on (A) hardness and (B) cohesiveness of cooking bananas upon cooking and cooling. Curves: (a) cooled bananas (b) cooked bananas 


\subsection{Effect of Added Starch on Hardness}

Upon cooking, hardness of starch-treated bananas $(1.06$ to $1.97 \mathrm{~N})$ was higher than that of the control $(0.86 \mathrm{~N})$ and increased with increasing starch concentration (Figure 2A, curve (b). Hardness increased from 1.06 (1.7\%) to $1.97 \mathrm{~N}(11.7 \%$ added starch) becoming significantly higher than the control beyond $5 \%$ added starch $(\mathrm{P}<0.05)$ with a strong positive correlation of $98.2 \%$. Upon cooling, hardness increased for both the control $(4.04 \mathrm{~N})$ and starch-treated bananas ( 4.52 to $5.99 \mathrm{~N}$ ) (Figure 2A, curve (a), which could be attributed to starch retrogradation. Hardness of cooled starch-treated bananas was higher than that of the control and increased significantly with increasing starch concentration from 4.52 at $1.7 \%$ to $5.99 \mathrm{~N}$ at $11.7 \%(\mathrm{P}<0.05)$ with a strong positive correlation of $83.4 \%$.

Cohesiveness of starch-treated bananas $(0.91$ to $1.56 \mathrm{~N})$ was also higher than that of the control $(0.84 \mathrm{~N})$ and increased with increasing added-starch concentration from $0.91(1.7 \%)$ to $1.56 \mathrm{~N}$ (11.7\% added starch) upon cooking with a strong positive correlation of $98.3 \%$ (Figure 2B, curve (b). Upon cooling, cohesiveness of the control and starch-treated bananas generally increased due to starch retrogradation. However, cohesiveness of starch-treated bananas $(3.20$ to $4.49 \mathrm{~N})$ was significantly higher than that of the control $(2.34 \mathrm{~N})$ and increased significantly with increasing starch concentration from $3.20(1.7 \%)$ to $4.49 \mathrm{~N}(8.3 \%$ added starch $)(\mathrm{P}<0.05)$ before decreasing slightly to $3.65 \mathrm{~N}$ at $11.7 \%$ added starch with a correlation coefficient of $54 \%$ (Figure $2 \mathrm{~B}$, curve (a).
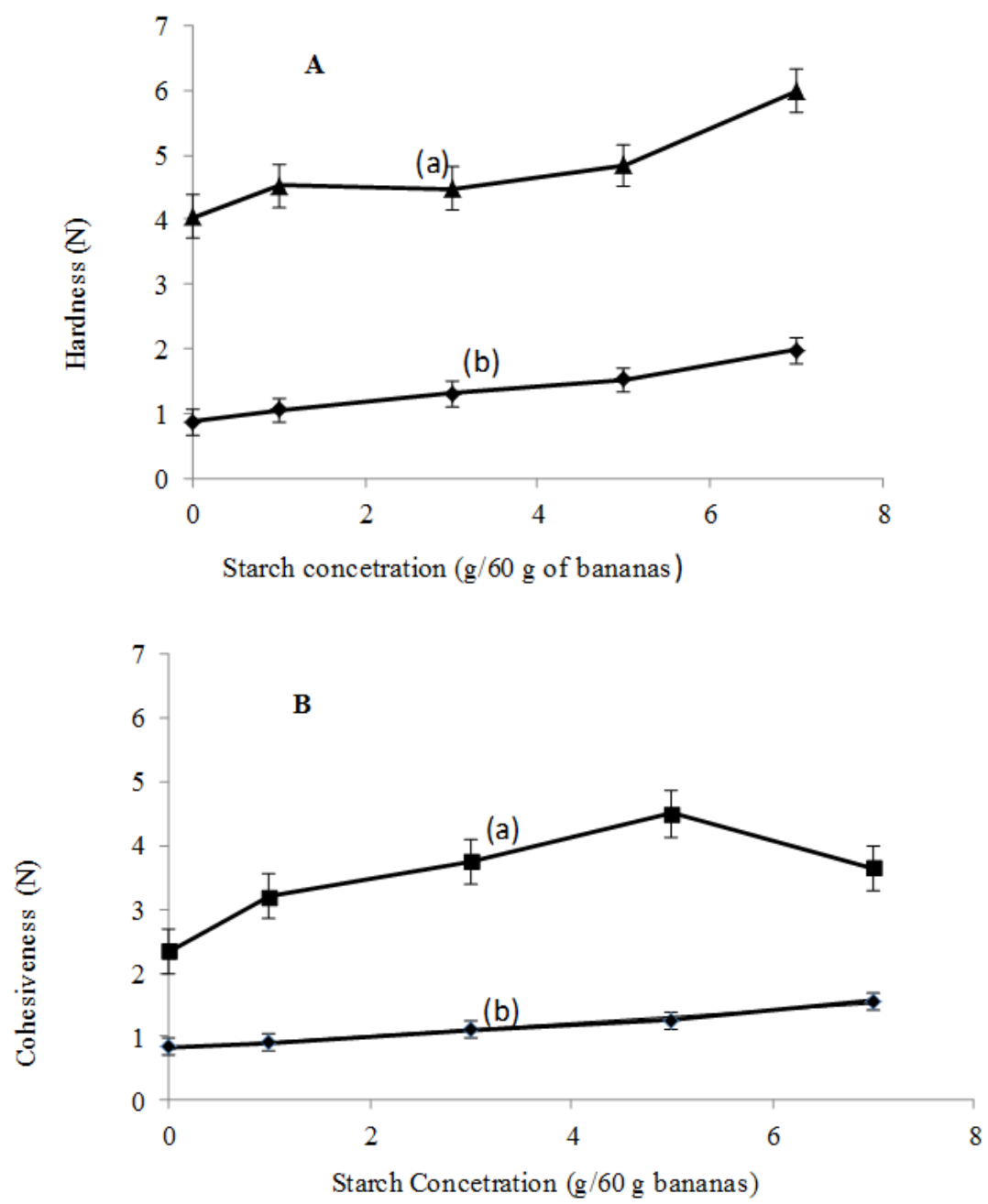

Figure 2. Effect of added starch on (A) hardness and (B) cohesiveness of cooking bananas upon cooking and cooling. Curves: (a) cooled bananas (b) cooked bananas

\subsection{Effect of Starch-pectin Composite on Hardness}

Upon cooking, hardness of starch-pectin composite treated bananas ranged between 1.42 and $1.15 \mathrm{~N}$ and was 
generally harder than the control $(0.89 \mathrm{~N})$ but not significantly different $(\mathrm{P}>0.05)$ (Figure $3 \mathrm{~A}$, curve (b). Hardness was $1.42 \mathrm{~N}$ at $3.33 \%$ composite which was significantly higher than the control $(\mathrm{P}<0.05)$ and decreased to $1.15 \mathrm{~N}$ at $10 \%$ composite but then increased to 1.33 and $1.37 \mathrm{~N}$ at 16.6 and $23.4 \%$ composites, respectively. Upon cooling, hardness generally increased for each of the control and starch-pectin composite treated bananas due to starch retrogradation (Figure 3A, curve (a). Hardness of the control $(4.76 \mathrm{~N})$ was generally higher than that of the composite treated bananas (4.43 to $2.77 \mathrm{~N})$ but not significantly different $(\mathrm{P}>0.05)$. Hardness of cooled bananas decreased from 4.43 at $3.33 \%$ to $2.77 \mathrm{~N}$ at $10 \%$ composite but then rose to $3.16 \mathrm{~N}$ at $16.6 \%$ and finally to $4.91 \mathrm{~N}$ at $23.4 \%$ composite.

Cohesiveness of the starch-pectin composite treated bananas $(1.09$ to $1.38 \mathrm{~N})$ was higher than that of the control $(0.86 \mathrm{~N})$ upon cooking but not significantly different $(\mathrm{P}>0.05)$ (Figure $3 \mathrm{~B}$, curve (b). Cohesiveness decreased from 1.30 at $3.33 \%$ to $1.09 \mathrm{~N}$ at $10 \%$ composite and then increased to 1.26 and $1.38 \mathrm{~N}$ at 16.6 and $23.4 \%$ composite, respectively. Upon cooling, cohesiveness of the control $(2.83 \mathrm{~N})$ and that of the composite-treated bananas ( 2.13 to $3.76 \mathrm{~N}$ ) generally increased due to starch retrogradation (Figure 3B, curve (a). Cohesiveness at $3.33 \%$ composite was 2.80 which decreased to $2.13 \mathrm{~N}$ at $10 \%$ composite but rose up to 2.47 and $3.76 \mathrm{~N}$ at 16.6 and $23.4 \%$ composite, respectively.
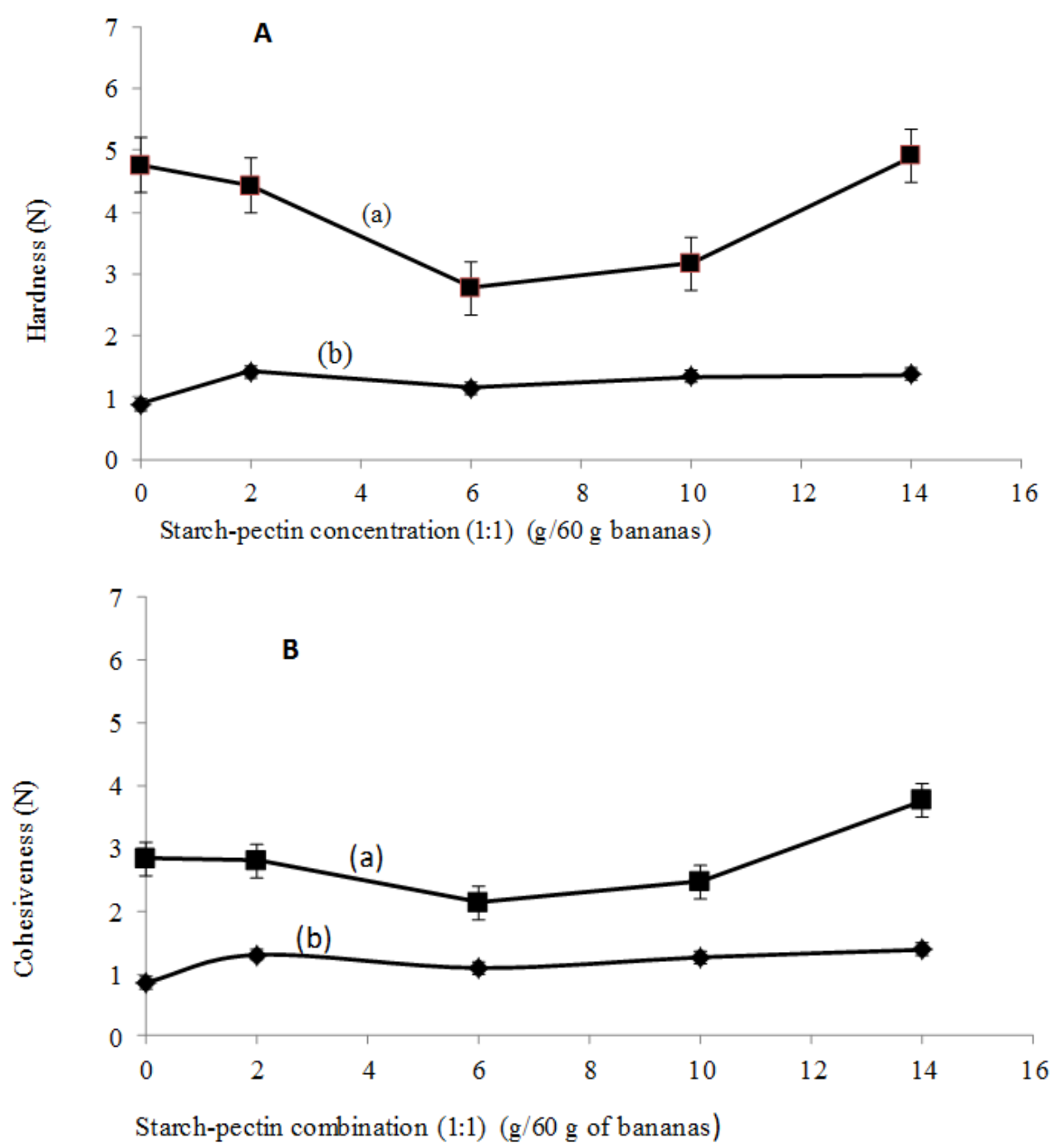

Figure 3. Effect of added starch-pectin composite on (A) hardness and (B) cohesiveness of cooking bananas upon cooking and cooling. Curves: (a) cooled bananas (b) cooked bananas

\subsection{Effect of Pectinase (Polygalacturonase) Treatment on Hardness}

The experiment was conducted within recommended optimum temperature and $\mathrm{pH}$ range for PG catalytic activity which vary between 45 and $55^{\circ} \mathrm{C}$ and 4.4 to 7.2 , respectively depending on the enzyme source and environment 
(Duvetter, Sila, Van Buggenhout, Van Loey, \& Hendrickx, 2009). The aim of this experiment was to establish if structural elimination of pectin from the bananas has a significant effect on hardness during cooking and upon cooling.

Results indicated that all pectinase-treated bananas were significantly harder than the controls $(\mathrm{P}<0.05)$ during cooking and upon cooling (Figures 4A and 5A). During cooking, hardness of pectinase-treated cooking bananas decreased with cooking time from 1.82 to $1.23 \mathrm{~N}$ relative to that of the control which fluctuated between 0.56 and $0.61 \mathrm{~N}$ (Figure $4 \mathrm{~A}$, curve (b). Hardness of pectinase treated juice bananas was also significantly higher than that of the control $(\mathrm{P}<0.05)$ and decreased from 3.49 to $1.80 \mathrm{~N}$ relative to the control which decreased from 1.78 to 1.57 during cooking (Figure 5A, curve (a). Upon cooling, hardness of pectinase-treated bananas and the controls increased significantly $(\mathrm{P}<0.05)$ probably due to starch retrogradation (Table 1). The cooled pectinase-treated bananas were significantly harder than their respective controls $(\mathrm{P}<0.05)$. Hardness of cooled pectinase-treated cooking bananas was $6.62 \mathrm{~N}$ while that of its corresponding control was $3.62 \mathrm{~N}$. Hardness of cooled pectinase-treated juice bananas was $15.36 \mathrm{~N}$ while that of its corresponding control was $12.34 \mathrm{~N}$.

Cohesiveness of pectinase-treated cooking bananas was significantly higher than that of the control and decreased from 1.47 to $1.10 \mathrm{~N}$ (Figure 4B, curve (a) while that of the control decreased from 0.61 to $0.57 \mathrm{~N}$ during cooking (Figure 4B, curve (b). Cohesiveness of the pectinase-treated juice bananas decreased from 2.47 to $1.26 \mathrm{~N}$ (Figure 5B, curve (a) while that of the control decreased from 1.47 to $1.23 \mathrm{~N}$ (Figure 5B, curve (b) and was not significantly different $(\mathrm{P}>0.05)$. Upon cooling, cohesiveness of the pectinase-treated bananas and the controls generally increased due to starch retrogradation. Cohesiveness of the cooled pectinase-treated cooking bananas was $5.12 \mathrm{~N}$ which was significantly higher than $2.63 \mathrm{~N}$ of the control (Table 1). Cohesiveness of cooled pectinase-treated juice bananas was $6.83 \mathrm{~N}$ which was not significantly different from $6.50 \mathrm{~N}$ of the control (Table 1).
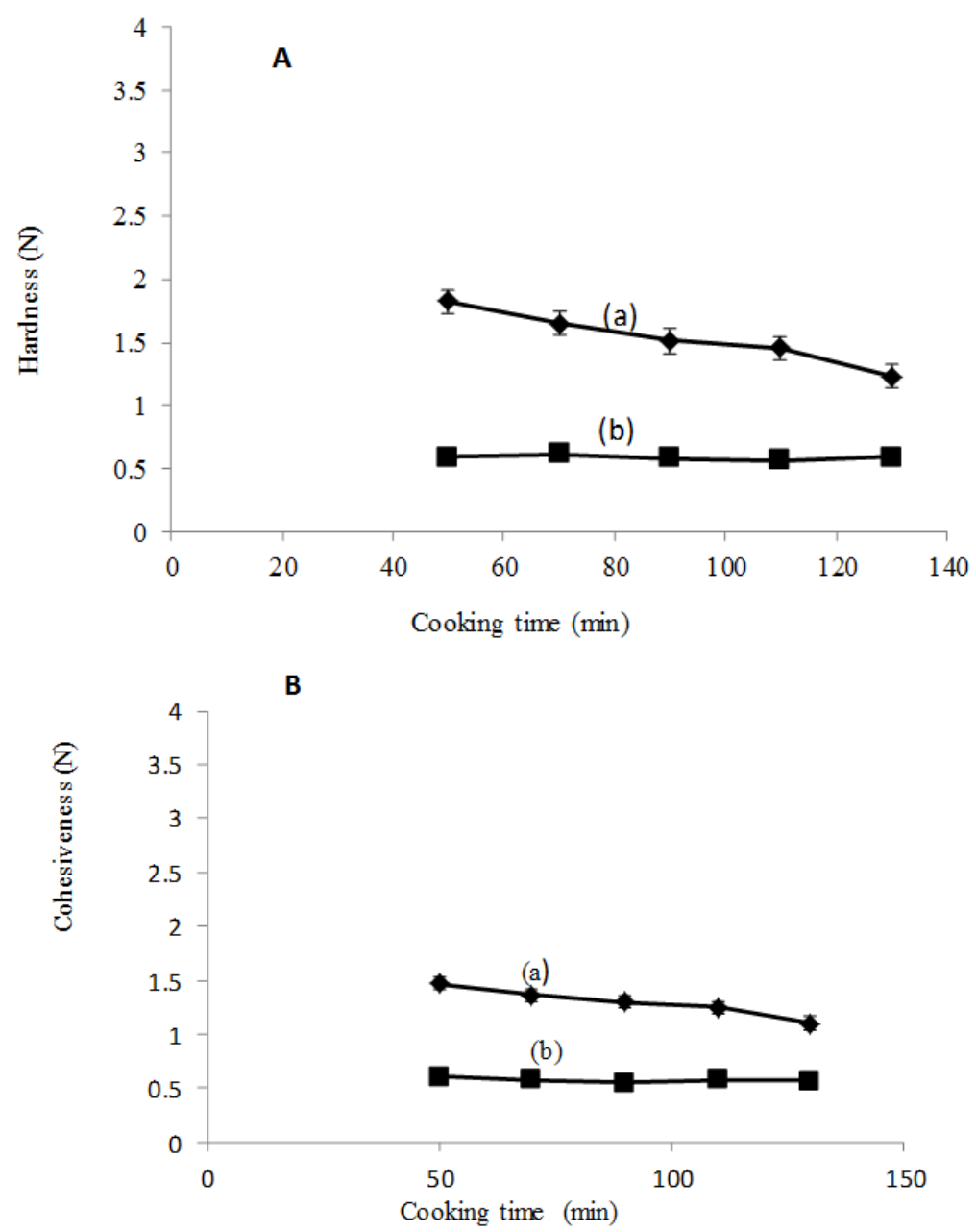

Figure 4. Effect of structural elimination of pectin on (A) hardness and (B) cohesiveness of cooking bananas

(KAZ) during cooking. Curves: (a) Pectinase-treated bananas (b) Control 

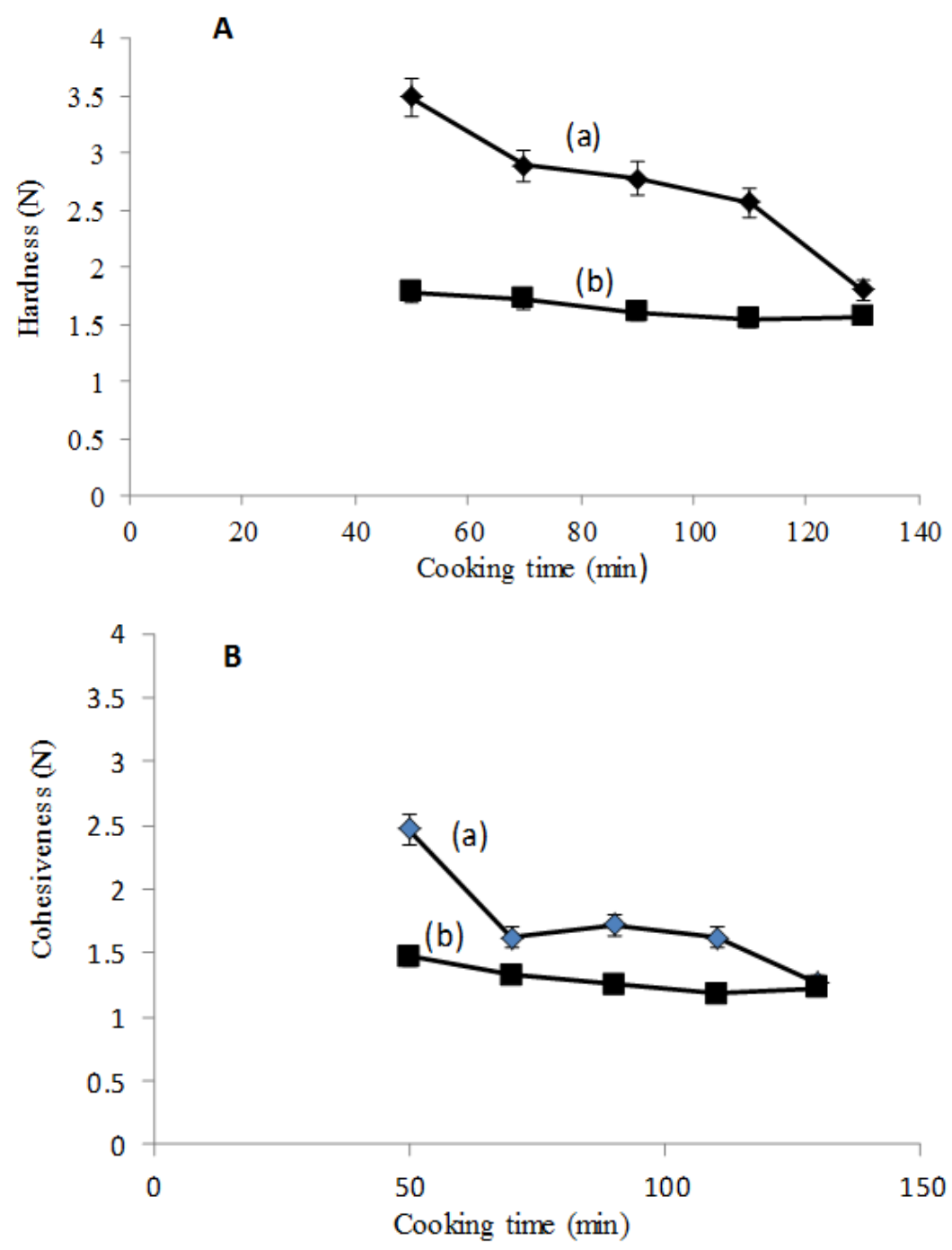

Figure 5. Effect of structural elimination of pectin on (A) hardness and (B) cohesiveness of juice bananas (KAY) during cooking. Curves: (a) cooled bananas (b) cooked bananas

Table 1. Effect of structural elimination of pectin on hardness of cooled bananas after cooking

\begin{tabular}{|c|c|c|c|c|}
\hline \multirow[t]{3}{*}{ Treatment } & \multicolumn{4}{|l|}{ Texture } \\
\hline & \multicolumn{2}{|c|}{ Hardness (N) } & \multicolumn{2}{|c|}{ Cohesiveness (N) } \\
\hline & Treated & Control & Treated & Control \\
\hline \multicolumn{5}{|l|}{ Cooking bananas } \\
\hline Cooked for $130 \mathrm{~min}$ & $1.23 \pm 0.27^{\mathrm{a}}$ & $0.59 \pm 0.07^{b}$ & $1.10 \pm 0.21^{\mathrm{a}}$ & $0.57 \pm 0.09^{b}$ \\
\hline After cooling (4 h) & $6.63 \pm 1.59^{\mathrm{a}}$ & $3.62 \pm 0.59^{b}$ & $5.12 \pm 0.56^{\mathrm{a}}$ & $2.63 \pm 0.15^{b}$ \\
\hline \multicolumn{5}{|l|}{ Juice bananas } \\
\hline Cooked for $130 \mathrm{~min}$ & $1.80 \pm 0.21^{\mathrm{b}}$ & $1.57 \pm 0.10^{\mathrm{b}}$ & $1.26 \pm 0.31^{\mathrm{d}}$ & $1.23 \pm 0.11^{\mathrm{d}}$ \\
\hline After cooling (4 h) & $15.36 \pm \mathrm{a}$ & $12.34 \pm 0.88^{\mathrm{b}}$ & $6.83 \pm 1.45^{\mathrm{d}}$ & $6.50 \pm 0.13^{\mathrm{d}}$ \\
\hline
\end{tabular}

Values with same superscript letters along the same row under the same subheading are not significantly different $(P>0.05)$.

\section{Discussion}

\subsection{Introduction}

The changes that starch undergoes during gelatinization and retrogradation are major determinants of its functional properties for food processing, during digestion, and in industrial applications. These properties 
determine the quality, acceptability, nutritional value, and shelf-life of the finished foods (Wang \& Copeland, 2013). Starch retrogradation has been the subject of intensive research throughout the last half century resulting in a vast body of literature (Wang et al., 2015). The effects of starch retrogradation including its addition to certain foods have also been widely covered (Sozer, Dalgic, \& Kaya, 2007; Liu, Nie, \& Chen, 2013; Steeneken, Woortman, \& Oudhuis, 2011). However, this has not been established on bananas before and hence the importance of the current study. On the other hand, pectin is associated with firmness of living plant tissues as well as processed products where its demethylation leads to divalent cations reacting with the carboxyl groups to form pectates which precipitate and cause increased firmness. However, the effect of adding pectin or its structural elimination on the textural hardness of bananas upon cooking and cooling has not been investigated before.

\subsection{Effect of Pectin on Hardness and Cohesiveness of Bananas}

Pectin of $75 \%$ D.E was applied on bananas at the rate of $0 \%, 1.7 \%, 5 \%, 8.3 \%$ and $11.7 \%$. Results indicated that pectin-treated bananas were slightly harder than the control upon cooking but were not significantly different ( $\mathrm{P}>0.05)$. However, upon cooling, hardness of pectin-treated bananas was lower than that of the control and decreased with increasing pectin concentration up to $5 \%$ and then rose again, implying that at lower concentrations, pectin enhances tenderness particularly during cooling of cooked bananas. The observed increase in hardness upon cooking of bananas could be attributed to a number of factors: adhesiveness of pectin leading to increased compactness of starch and other molecules; inadequate gelatinization of starch due to the high Water Binding Capacity (WBC) of pectin (Lobato-Calleros, Ramos-Solís, Santos-Moreno, \& Rodríguez-Huezo, 2006) making it unavailable for starch to gelatinize adequately; the increased dry matter content due to added pectin. The weak correlation (18.3\%) between hardness and added pectin is a manifestation that pectin has little effect on increasing hardness in cooked bananas. These results are in agreement with Tan, Ye, Singh, \& Hemar (2007) who observed an increase in stiffness of rennet gels and a reduction in syneresis as the concentration of high methoxyl pectin increased from $0 \%$ to $0.1 \%$ attributed to a more compact microstructure. Kopjar, et al. (2009) also found that pectin increases the firmness and cohesiveness of strawberry jam which increases with increasing degree of esterification of pectin. These authors attributed this to increased adhesiveness and compactness of the molecules. Upon cooling, there was a general increase in hardness of pectin-treated bananas and the control which may be attributed to starch retrogradation (Wang et al., 2015). Retrogradation is accompanied by a series of physical changes such as exudation of water and increased crystallinity with the appearance of $\beta$-type crystalline polymorphs (Hoover, Hughes, Chung, \& Liu, 2009). However, hardness decreased with increasing pectin concentration which was associated with a strong a negative correlation of $80 \%$. The observed decrease in hardness of pectin-treated bananas upon cooling may be attributed to the High Water Retention Capacity (WRC) of pectin. Pectin is highly hygroscopic and absorbs water leading to formation of soft gels. The high water binding and holding capacity of pectin (Armstrong, Eastwood, \& Brydon, 1993) may keep the cooked banana structural matrix moist, thus maintaining starch in a gelatinized state hence making pectin-treated bananas relatively soft in cooled form. Pectins absorb varying amounts of water, for instance sunflower seed pectin absorbs about $57 \mathrm{~g}$ of water per $\mathrm{g}$ of pectin (Miyamoto \& Chang, 1992). Apple pectin has high methoxyl content with DE higher than $50 \%$ and a water holding capacity of approx. $6.7 \mathrm{~g}$ water/g pectin (Sri Puvanesvari, Yogeshini, Noranizan, \& Kharidah, 2012). According to Sri Puvanesvari et al. (2012), apple pectin also has a high emulsifying activity of $90 \%$ and above implying that pectin can prevent loss of water from the food matrix hence preventing extensive starch retrogradation. Studies on cheese with added pectin have found increased moisture content coupled with reduced hardness (Ibáñez, Waldron, \& McSweeney, 2016; Lobato-Calleros et al., 2006). Added pectin may also interrupt interactions between starch molecules within the cooked banana matrix hence preventing re-crystallization of starch leading to a decrease in hardness.

Cohesiveness of pectin-treated bananas was higher than the control and increased slightly with increase in pectin concentration upon cooking coupled with a strong positive correlation of $81 \%$. Pectin has adhesive properties which could keep particles in the cooked banana matrix cohesive. Upon cooling, the untreated control was more cohesive than all pectin-treated banana samples whose cohesiveness decreased with increasing pectin concentration coupled with a strong negative correlation $82 \%$. This implies that pectin reduces cohesion and hence confers tenderness in cooked bananas. The decreasing cohesiveness in cooled bananas could be due to high moisture levels retained by added pectin. This may be true only in the short run. Kopjar, et al. (2009) found that the cohesiveness of all pectin treated jam samples had increased over the storage period which may be due to loss of moisture causing structural re-arrangement and increased adhesiveness and hence cohesiveness.

\subsection{Effect of Added Starch on Hardness and Cohesiveness of Bananas}

Starch-treated bananas were significantly harder than the control upon cooking and cooling $(\mathrm{P}<0.05)$ and 
hardness increased with increasing starch concentration with a strong positive correlation of $98.2 \%$. This implies that starch increases hardness in cooked bananas. Despite the high Water Binding Capacity (WBC) particularly during heating, starch has a low Water Holding Capacity (WHC) which tends to reduce the water activity (aw) of foods (Homayouni et al., 2013). This property coupled with increased dry matter content possibly enhances increased hardness during cooking of bananas. Upon cooling, there was a general increase in hardness of starch-treated bananas and the control which could be due to starch retrogradation. Retrogradation of starch involves re-association of gelatinized starch (amylose) molecules to form an ordered crystalline structure (Eliasson \& Wahlgren, 2004) associated with increased solidity and hence hardness. Upon cooling, hardness increased with increasing starch concentration. These results are in agreement with findings by Liu et al.(2013) who found a significant increase in hardness of Surimi gels $(\mathrm{P}<0.05)$ prepared with added corn starch. The starch used in this study was freshly extracted from the Nakitembe banana cultivar at green mature stage to avoid wide variation. Due to differences in physicochemical properties, different starches may differ in their influence on hardness of cooked bananas. Noodles made from starches isolated from several specific potato varieties were harder and more cohesive than other starch noodles (Kim, Wiesenborn, Lorenzen, \& Berglund, 1996; Singh, Singh, \& Sodhi, 2002). According to Toyama, Miura, \& Taneya (1997), use of sweet potato, corn, and cassava starches in noodles was found to increase firmness. They also found that noodles supplemented with potato starch were firmer than those supplemented with other starches.

Cohesiveness is a good indicator of how the banana sample holds together upon cooking and may be directly affected by adhesiveness of the sample which in turn relates to the amount of starch and starch gelatinization (Sozer et al., 2007). There was a high correlation (98.3\%) between cohesiveness of the bananas and starch concentration upon cooking implying that starch strongly increases cohesiveness. This may be attributed to the adhesive nature of gelatinized starch being more in samples with more starch. Upon cooling, cohesiveness was observed to increase with starch concentration though with a reduced correlation of $54.3 \%$ implying less adhesiveness of starch as the bananas cooled. Upon cooling, starch loses water (or its gelatinized state) leading to retrogradation and this increases fragility of cooked bananas. Beyond $8.3 \%$ added starch, there was a sudden decrease in cohesiveness (Figure 2B, curve (a). These results are in agreement with findings by Kim et al. (1996) and Singh et al. (2002) who found noodles made from starches to be cohesive with those made using different potato starches being more cohesive than those made using other starches. However, these results contrast the findings by Liu et al. (2013) who did not find starch to have a significant influence on cohesiveness of Surimi gels $(p<0.05)$.

\subsection{Effect of Starch-pectin Composite on Hardness and Cohesiveness of Bananas}

Application of starch-pectin composite generally resulted in increased hardness of bananas upon cooking which was observed to decrease and then increase again with increasing starch-pectin composite concentration. However, hardness was not far from that of starch alone or pectin alone treated bananas and was not significantly different from the control $(\mathrm{P}>0.05)$. Upon cooling, there was a general increase in hardness of composite treated bananas and the control which could be attributed to starch retrogradation. Upon cooling, hardness decreased from 4.43 to $2.77 \mathrm{~N}$ at $3.33 \%$ and $10 \%$ but suddenly increased to 3.16 and $4.91 \mathrm{~N}$ at 16.6 and $23.4 \%$ composite, respectively. The trend of these results was similar to that observed for pectin-treated bananas. Upon cooling, hardness of the control and the composite-treated bananas was not significantly different $(\mathrm{P}>0.05)$.

The high water binding and holding capacity of pectin could have had a significant effect on the properties of the composite and hence hardness of the composite-treated bananas. Pectin remains gelatinized long enough to cause a considerable proportion of starch also to remain gelatinized which reduces the extent of starch retrogradation and firming. Pectin may also have a diluting effect on starch by occupying intermolecular spaces between starch molecules. This keeps starch molecules apart and possibly prevents extensive re-association that would cause formation of a crystalline structure hence reducing hardness. However, as the concentration of starch-pectin composite increases beyond $16.6 \%$, there was increased hardness upon cooling. This could be due to increased competition for water between starch and pectin which becomes significantly depleted. As a result, both starch and pectin possibly start forming lumps that possibly increase hardness.

The increase in hardness upon cooling of the composite treated bananas was also accompanied by an increase in cohesiveness. Generally, cohesiveness of starch-pectin composite treated bananas was higher than the control and decreased initially but then increased with increasing composite concentration upon cooking. The increase in cohesiveness relative to the control may be attributed to increased adhesiveness of starch and pectin upon gelatinization. From starch and pectin single treatment results, starch appears to contribute more to cohesiveness than pectin. The cohesiveness values of the composite-treated bananas $(1.09$ to $1.38 \mathrm{~N})$ were closer to those of starch-treated bananas ( 0.91 to $1.56 \mathrm{~N}$ ) implying that starch may have more influence on cohesiveness than 
pectin. Upon cooling, cohesiveness appears to decrease up to a certain level and then increase.

\subsection{Effect of Pectinase (Polygalacturonase) on Hardness of Bananas}

To better understand the effect of pectin on hardness of bananas, the molecule was structurally eliminated from the banana matrix using pectinase (Polygalacturinase) enzyme. All bananas that were treated with pectinase were found to be significantly harder than the control $(\mathrm{P}<0.05)$ upon cooking and cooling. This implies that the enzyme pectinase was able to hydrolyze and eliminate pectin from the structural matrix of bananas. Hydrolysis of pectin leaves starch and cellulose/hemicellulose as the main structural elements that profoundly affect texture. This could have resulted in a significant increase in hardness of all bananas from which pectin was hydrolyzed during cooking and upon cooling. Polygalacturonase (PG) cleaves the $\alpha-1$, 4-D galacturonan linkages in the pectin homogalacturonan chain by hydrolysis preferring the non-esterified substrate with decreasing activity as the degree of methoxylation increases. ExoPG attacks the chain from the non-reducing end and removes terminally $(1 \rightarrow$ )-linked GalA residues (Duvetter et al., 2009). Removal of pectin leaves starch as the main structural component which has been shown in the current study to increase hardness of bananas upon cooking and cooling. Starch has a high Water Binding Capacity (WBC) (upon heating) but also a low Water Holding Capacity (WHC) upon cooling which leads to reduced water activity (Homayouni et al., 2013) of the bananas. The absence of pectin in the structural matrix of bananas appears to reduce water activity which in turn reduces the extent of starch gelatinization during cooking leading to increased hardness. It was observed during sample preparation that pectinase-treated bananas appeared dryer than the control. Pectinase treated juice bananas were harder than cooking bananas. This is because juice bananas contain more starch than cooking bananas (Gafuma et al., 2018) which means the more starch in the bananas, the harder the texture as evidenced in this work. In all cases, hardness reduced with cooking time between 50 and $130 \mathrm{~min}$ but still the pectinase-treated bananas remained significantly harder than the controls. The decrease in hardness with cooking time could be due to the increasing degree of starch gelatinization as more starch takes up moisture from the steam. In general, these results imply that presence of pectin in the structural matrix of bananas significantly increases tenderness during cooking and cooling. These findings also re-enforce earlier results where we have shown that added pectin decreases hardness in cooked bananas particularly upon cooling. This could be explained by the high Water Binding and Holding Capacities of pectin which help to keep starch gelatinized longer leading to increased tenderness of cooked bananas.

Cohesiveness measures the extent to which a food product stays together after deformation or the extent to which a product adheres to itself under some compressive or tensile stress. Current results indicated that there was a significant increase in cohesiveness of bananas from which pectin was hydrolyzed which decreased with cooking time while that of the control remained more or less constant. This implies that pectin lowers cohesiveness relative to starch. The increased cohesiveness of bananas due to pectin elimination would probably improve their processability as the product becomes more tolerant of manufacturing, packaging and delivery stresses. This enhances presentation of the product to the consumers in its expected state (Texture technologies Corp. and Stable Micro Systems, Ltd, 2018). However, the increased hardness found in this study would make the product undesirable to consumers who prefer tender banana products. Upon cooling, final cohesiveness of the cooled pectinase-treated juice bananas was not significantly different from that of the control.

Generally, the cooked starch-treated bananas were 1.3 times (130\%) harder than pectin treated bananas. Also, hardness of cooled starch-treated bananas was 1.89 times (189\%) harder than the cooled pectin-treated bananas. This implies that starch increases hardness more than pectin does. Current results showed that pectin decreases hardness in bananas particularly during the cooling phase probably due to its high Water Binding, Water Holding and Emulsifying Capacities. According to these results, pectin contributes to tenderness of bananas as observed in cooked and cooled bananas. Unlike starch, pectin has a tendency of remaining gelatinized in heated and cooled forms which may enhance the gelatinized state of banana starch.

Based on these results, the optimal concentration of pectin that can be added to enhance tenderness of cooked bananas without profoundly affecting other properties is between 1.7 and 5\%. Removal of pectin from bananas using pectinase increases hardness in cooked and cooled bananas. Absence of pectin in the structural matrix of bananas encourages starch-starch molecular interactions leading to increased hardness. It was observed in this work that cohesiveness and hardness are positively correlated under cooking and cooling conditions. Both starch and pectin were found to increase cohesiveness during cooking. However, upon cooling, pectin appears to decrease cohesiveness while starch increases it.

\section{Conclusions and recommendations}

Starch increases hardness of bananas during cooking and cooling. Pectin has minimal effect on hardness of 
bananas upon cooking but strongly decreases it during cooling. This implies that pectin favors tenderness in cooled bananas after cooking. Hence pectin should be added to bananas at optimal levels (1 - 5\%) to enhance tenderness. Co-presence of starch and pectin increases cohesiveness of bananas upon cooking while pectin alone decreases it upon cooling.

Structural hydrolysis and elimination of pectin from the banana matrix significantly increases their hardness during cooking and upon cooling. These findings highlight the importance of pectin in enhancing tenderness of cooked bananas. There is the need to optimize pectin levels (1.7-5\%) during cooking for tenderer, tastier and better appealing banana meals.

\section{Acknowledgement}

This work was funded by the African Development Bank (AfDB) under the AfDB - V- HEST Project in the Ministry of Education and Sports of Uganda. Authors are very grateful to Prof. Archileo Kaaya, Prof. Yusuf B. Byaruhanga and Mr. Joseph Balamaze of Food Science and Nutrition Department, Makerere University for their technical support.

\section{References}

Armstrong, E., Eastwood, M., \& Brydon, W. (1993). The influence of wheat bran and pectin on the distribution of water in rat caecal contents and faeces. British Journal of Nutrition, 69(3), 913-920. https://doi.org/10.1079/BJN19930091

Bourne, M. (2002). Food texture and Viscosity: Concept and Measurement (2nd Edition ed.). London: Elsevier.

Duvetter, T., Sila, D., Van Buggenhout, S., Jolie, R., Van Loey, A., \& Hendrickx, M. (2009). Pectins in Processed Fruit and Vegetables: Part I-Stability and Catalytic Activity of Pectinases. Comprehensive Reviews in Food Science and Food Safety. Willey Online Library, 8(2), 75-85. https://doi.org/10.1111/j.1541-4337.2009.00070.x.

Eliasson, A., \& Wahlgren, M. (2004). Starch-lipid interactions and their relevance in food products. In A. Eliasson, Starch in Food: Structure, Function and Applications, 441-460. https://doi.org/10.1533/9781855739093.3.441

Espinosa - Solis, V., Jay - lin, J., \& Bello - Perez, L. (2009). Physicochemical Characteristics of Starches from Unripe Fruits of Mango and Banana. Starch, 61(5), 291-299. https://doi.org/10.1002/star.200800103 .

Gafuma, S., Byarugaba-Bazirake, G., \& Mugampoza, E. (2018). Textural Hardness of Selected Ugandan Banana Cultivars under Different Processing Treatments. Journal of Food Research, 7(5). https://doi.org/10.5539/jfr.v7n5p98.

Gummadi, S., \& Panda, T. (2003). Purification and biochemical properties of microbial pectinases-a review. Process Biochemistry. Elesevier, 38(7), 987-996. https://doi.org/10.1016/S0032-9592(02)00203-0.

Homayouni, A., Amini, A., Keshtiban, A., Mortazavian, A., Esazadeh, K., \& Pourmoradian, S. (2013). Resistant starch in food industry: A changing outlook for consumer and producer. A review. Starch, 65, 1-13. https://doi.org/10.1002 star.201300110.

Hoover, R., Hughes, T., Chung, H.-J., \& Liu, Q. (2009). Composition, molecular structure, properties, and modification of pulse starches: A review. Food Research International, 43(2), 399-413. https://doi.org/10.1016/j.foodres.2009.09.001 .

Ibáñez, R., Waldron, D., \& McSweeney, P. (2016). Effect of pectin on the composition, microbiology, texture, and functionality of reduced-fat Cheddar cheese. Dairy Science \& Technology , 96, 297-316. doi:10.1007/s13594-015-0265-y.

Jongen, W. (2002). Fruit and Vegetable Processing. Improving quality. (Second Edition ed.). Woodhead Publishing, Elsevier.

Karamura, D. (1998). Numeric Taxonomic studies of the East African Highland Bananas (Musa AAA-East Africa) in Uganda. Montpellier, France .

Kim, Y., Wiesenborn, D., Lorenzen, J., \& Berglund, P. (1996). Suitability of edible bean and potato starches for starch noodles. Cereal Chem, 73, 302-3028.

Kopjar, M., Piližota, V., Tiban, N., Šubarić, D., Babić, J., Ačkar, D., et al. (2009). Strawberry Jams: Influence of Different Pectins on Colour and Textural Properties. Czech Journal of Food Science, 27(1), 20-28. https://doi.org/10.17221/95/2008-CJFS 
Liu, H., Nie, Y., \& Chen, H. (2013). Effect of Different Starches on Colors and Textural Properties of Surimi-Starch Gels. International Journal of Food Properties, 17(7), 1439-1448. https://doi.org/10.1080/10942912.2012.680224.

Lobato-Calleros, C., Ramos-Solís, L., Santos-Moreno, A., \& Rodríguez-Huezo, M. (2006). MICROSTRUCTURE AND TEXTURE OF PANELA TYPE CHEESE-LIKE PRODUCTS: USE OF LOW METHOXYL PECTIN AND CANOLA OIL AS MILK-FAT SUBSTITUTES . Amidiq , 5, 71-79 .

Miyamoto, A., \& Chang, K. (1992). Extraction and Physicochemical Characterization of Pectin from Sunflower Head Residues. Journal of Food Science, 57(6), 1439-1443. https://doi.org/10.1111/j.1365-2621.1992.tb06878.x .

Payasi, A., Mishra, N., Chaves, A., \& Singh, R. (2009). Biochemistry of fruit softening: An overview. Physiology and Molecular biology of Plants, 15(2), 103-13. https://doi.org/10.1007/s12298-009-0012-z .

Sharma, N., Rathore, M., \& Sharma, M. (2012). Microbial pectinase: sources, characterization and applications. . Reviews in Environmental Science and Bio/Technology. https://doi.org/10.1007/s11157-012-9276-9.

Singh, N., Singh, J., \& Sodhi, N. (2002). Morphological, thermal, rheological and noodle-making properties of potato and corn-starch. J. Sci. Food Agric., 82, 1376-1383. https://doi.org/10.1002/jsfa.1194

Sozer, N., Dalgic, A., \& Kaya, A. (2007). Thermal, textural and cooking properties of spaghetti enriched with resistant starch. Journal of Food Engineering, 81, 476-484. https://doi.org/10.1016/j.jfoodeng.2006.11.026.

Sri Puvanesvari, G., Yogeshini, R., Noranizan, M., \& Kharidah, M. (2012). Functional and Preliminary Characterisation of Hydrocolloids from Tamarillo (Solanum betaceum Cav.) Puree. Molecules, 17, 6869-6885. https://doi.org/10.3390/molecules17066869 .

Steeneken, P., Woortman, A., \& Oudhuis, A. (2011). Processing stability of cross-linked starches in acid sauce applications and identification of some of the molecular factors involved. Food Hydrocolloids, 25(3), 410-418. https://doi.org/10.1016/j.foodhyd.2010.07.009

Tan, Y., Ye, A., Singh, H., \& Hemar, Y. (2007, May). Effects of Biopolymer addition on the dynamic rheology and microstructure of Renneted skim milk systems. Journal of textural Studies, 38(3), 404-422. https://doi.org/10.1111/j.1745-4603.2007.00104.x .

Tapre, A. R., \& Jain, R. K. (2014). Pectinases: Enzymes for fruit processing industry. Mini Review. International Food Research Journal, 21(2), 447-453.

Texture technologies Corp. and Stable Micro Systems, Ltd. (2018). Overview of Texture Profile Analysis. Godalming, Surrey. United Kingdom: Stable Micro Systems. Retrieved from $\mathrm{http}: / /$ texturetechnologies.com/resources/texture-profile-analysis.

Toyama, R., Miura, M., \& Taneya, S. (1997). Effects of starch origin and contents on sensory properties of "Reimen" (Korean noodles). Nippon Chori Kagaku Kaishi, 30, 213-225 (in Japanese).

Wang, S., \& Copeland, L. (2013). Molecular disassembly of starch granules during gelatinization and its effect on starch digestibility: a review. Food Function, 4(11), 1564-80. https://doi.org/10.1039/c3fo60258c.

Wang, S., Li, C., Copeland, L., Niu, Q., \& Wang, S. (2015). Starch retrogradation: A comprehensive Review. Institute of Food Technologists, 14(5), 568-585. https://doi.org/10.1111/1541-4337.12143.

Zhang, P., Whistler, R., BeMiller, J., \& Hamaker, B. (2005). Banana starch: Production, physicochemical properties, and digestibility - A review. Carbohydrate Polymers, 59(4), 443-458. https://doi.org/10.1016/j.carbpol.2004.10.014.

\section{Copyrights}

Copyright for this article is retained by the author(s), with first publication rights granted to the journal.

This is an open-access article distributed under the terms and conditions of the Creative Commons Attribution license (http://creativecommons.org/licenses/by/4.0/). 